\title{
Automated management of engineering infrastructure of pools of different function
}

\author{
Lev Shirokov ${ }^{1}$, Pavel Chelyshkov ${ }^{1}$, and Evgeny Romanenko ${ }^{1, *}$ \\ ${ }^{1}$ Moscow State University of Civil Engineering, 129337, Moscow, Yaroslavskoe shosse, 26, Russia
}

\begin{abstract}
The main problems of operation of locations with the difficult air-and-water environment are considered in the article. Questions of maintenance of parameters of a microclimate in the pool are considered. Need of usage the control system of a microclimate, its efficiency, profitability and social effect of its implementation is described. The mathematical model of the thermal mode of location is constructed. Process of regulation of indoor temperature of the pool is considered.
\end{abstract}

\section{Introduction}

In the modern world, an important role in processes of people's activity is played by pools. They satisfy their requirements during rest, in everyday life, positively influencing their health. At the same time, pools are important also for an industrial application and are included in the construction industry. Studying of parameters influence of a microclimate on construction materials and designs is very important for various tasks of a construction. Pools as specialized grounds for testing of construction materials and designs are for this purpose demanded in waters are various environment conditions, including impact conditions directly. Effective use of pools provides a need for fixed maintenance for them of certain hydroclimatic parameters. Treat such parameters: humidity and air temperature, water temperature, chemical composition of water and air [1-2]. In specialized grounds or cameras for testing construction materials and designs, it is necessary to create and support still certain tasks in parameters of aggression of water and air environments. For ensuring the required parameters of environmental condition of pools, these objects need to be equipped with the corresponding engineering systems. Systems of water treatment, heating, ventilation, etc. concern to them. An important problem of these systems is not only stabilization of parameters, but also the solution of questions of optimization and adaptation in process of management of engineering systems in the conditions of numerous external and internal indignations [3-4]. The pool is a hydroclimatic object with difficult air-andwater indoor environment. Different types of pools differ to destination, on structure, on structures and pickings of engineering systems. In general, pools can be divided, as shown in fig. 1 , into set of.

\footnotetext{
*Corresponding author: roni1968@yandex.ru
} 


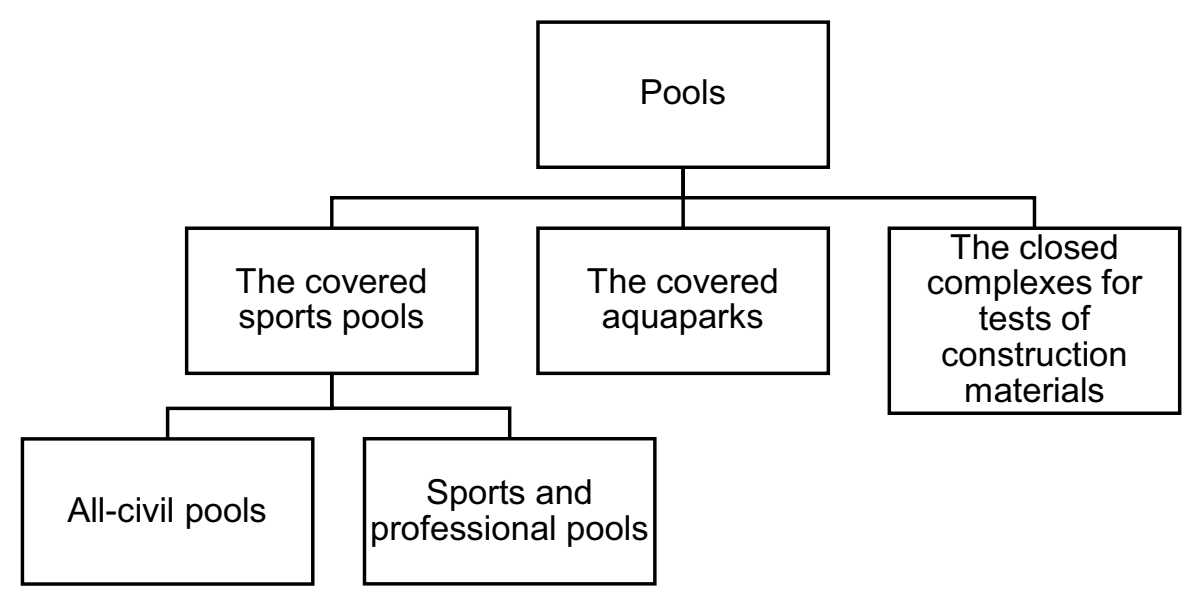

Fig. 1. The block diagram of pools on tasks

Constructions, climatic parameters and concentration of aggressive substances it is supported according to the requests made by technologists individually on each test. Besides, unlike swimming pools or aqua parks as from the point of view of temperature, so from the point of view of humidity and aggression of the environment the range of the supported parameters in a complex of tests is wider.

Systems of water treatment and heat supply are responsible for maintenance of water temperature in bowls of pools. The chemical composition of water in swimming pools and aqua parks is regulated by means of filters of rough and thin cleaning, and automatic systems of disinfecting [5-8]. In a complex for test of construction materials and designs, change of aggression of the environment is provided by the special installations dosing aggressive substances, spraying them in air or adding to water.

The wide range of the engineering systems applied on hydroclimatic objects makes increased requirements to a control system [4]. In complexes for tests, it is very important to support precisely the set parameters and to change them in time according to the set programs [7]. In aquaparks and sports pools, the problem of stabilization of climatic parameters is important. Along with the most important problem of providing the technological modes in all views of pools, it is necessary to resolve optimization issues. It is explained by high power consumption of the considered objects, large-scale consumption of resources and therefore it is important to economic expenditure of these resources to pay special attention.

Effective approach to creation of a management system capable to solve the problems considered above, synthesis of the integrated management system is. Implementation of the integrated adaptive systems provides need of development of the corresponding software and hardware complexes [8].

\section{Creation of mathematical model of the thermal mode of the room}


For synthesis of the integrated adaptive control system, it is necessary to conduct previously a complex research of an object, including making mathematical models of the operated processes.

Tasks of automation of maintenance of temperature conditions of air and water environments, which are determined by the current thermal modes in them, are most urgent for all types of pools.

The mathematical model of the thermal mode of rooms of [9-13] various pools can be generally provided by system of the equations:

where

$$
\left\{\begin{array}{l}
\sum_{i} G_{i}+\sum_{j} Q_{j}=0 \\
\sum_{i} M_{i}+\sum_{j} M_{j}=0
\end{array}\right.
$$

$Q_{i}$ - The convective heat transferred to internal air from internal surfaces of the protections and the surfaces of the equipment washed by this air;

$Q_{j}$ - The convective heat which is directly transferred to room air, for example, from heaters;

$M_{i}$ - Air streams through the protecting designs (an ex-filtration and an infiltration)

$M_{j}$ - The air streams, which are directly transferred to the room or deleted from him.

In system of the equations (1) the first equation - the equation of thermal balance of internal air and the second is the equation of air balance of the room.

For providing in the pool of the set thermal mode we will define amount of heat of $Q_{H E A T}$, which needs to be brought to the room a ratio from the equation of thermal balance:

$$
Q_{H E A T}=Q_{W A L L}+Q_{I N F}-Q_{I N . H .}=Q_{A L L}-Q_{I N . H .}=\frac{\mu+1}{\mu} Q_{I N F}-Q_{I N . H .}
$$

where

$Q_{W A L L}$ - Losses of heat through the protecting designs due to heat conductivity, W;

$Q_{I N F}$ - Losses of heat at the expense of an infiltration, W;

$Q_{I N . H .}-$ Internal thermal emissions, W;

$Q_{A L L}$ - Total losses of heat, W;

$\mu=\frac{Q_{I N F}}{Q_{W A L L}}-$ infiltration coefficient.

Internal thermal emissions include:

where

$$
Q_{I N . H .}=Q_{P E P}+Q_{C O M}+Q_{E Q U I P}+Q_{M A T}+Q_{R A D}+Q_{T P}
$$

$Q_{P E P}-$ The thermal emissions the people having a rest in the pool considering intensity of rest in water, $\mathrm{W}$; $\mathrm{W}$;

$Q_{\mathrm{COM}^{-}}$Thermal emissions communications and from the surfaces of the equipment,

$Q_{\text {EQUIP }}-$ Thermal emissions the electric equipment, W which is defined with the power of the equipment, coefficient of her use and simultaneity of his use, and a share of transition of electric energy to thermal.

$Q_{M A T}$ Thermal emissions heated materials and products, W;

$Q_{R A D^{-}}$Warmly from the solar radiation getting into the room, W;

$Q_{T P^{-}}$Thermal emissions at technological processes (moisture condensation, exothermic chemical reactions, etc.), $\mathrm{W}$.

At some technological processes, additional heatlosses can be created. It, in particular, occurs at liquid evaporation, which are considered in balance with a minus sign [12-17].

We will determine amount of heat spent for ventilation by a formula:

where

$$
Q_{V E N T}=G_{S P} * C_{S P} *\left(T_{S P}-T_{0}\right)
$$

$G_{S P}-$ Mass of affluent air, $\mathrm{kg} / \mathrm{h}$;

$C_{S P}-$ Specific heat of air, $\left(\mathrm{W}^{*} \mathrm{~h} / \mathrm{kg}^{* \circ} \mathrm{C}\right)$; 
$T_{S P}, T_{0}-$ Respectively temperature of affluent and external air, ${ }^{\circ} \mathrm{C}$.

For temperature of affluent air, we will write down:

where

$$
T_{S P}=T_{E X}+\frac{Q_{S P}}{G_{S P} * C_{S P}}
$$

$Q_{S P}-$ Amount of heat compensated by system of air heating, $\mathrm{W}$;

$T_{E X}$ - Air temperature, leaving the room, ${ }^{\circ} \mathrm{C}$.

For determination of mass of affluent air, we will accept a formula:

where

$$
G_{S P}=V * \rho * \lambda_{V}+G_{S P}^{+}
$$

$V$ - Volume of the building, cbm.;

$\rho$ - Density of air, $\mathrm{kg} / \mathrm{cbm}$;

$\lambda_{V}-$ Ventilation rate, $h^{-1}$; $\mathrm{kg} / \mathrm{h}$ :

$G_{S P}^{+}-$The mass of the external air coming to the room at the expense of an infiltration,

$$
G_{S P}^{+}=\sum_{i=1}^{n} G_{S P . i}^{+}
$$

Within, the objects considered in this article we would note that in grounds for test of building constructions, the room for carrying out test is configured by the principle of a thermos. Therefore, the thermal balance depends entirely on heat inflows of systems of ventilation and heating which cope automatic system of regulation, proceeding from the requirements specified by technologists in the application for test.

In swimming pools and aqua parks the main sources of heat receipt are systems of heating and ventilation, heat receipt from people and water in a bowl of the pool, an electric lighting. The main heat losses are connected with evaporation of water from the surface of the pool and roundabout paths, loss through the protecting designs and a glazing, and also from exhaust system of ventilation [16-18]. For minimization of losses of heat through exhaust system, it is equipped with heat utilizers, which transfer a part of heat (to $60-80 \%$ ) of exhaust air to affluent, reducing thereby load of system of heat supply and increasing profitability of system.

The corresponding equations of dynamics defining communications between input and output parameters are necessary for design of system of automatic control of temperature of the air environment of rooms of pools. In the case under consideration values of adjustable temperatures of rooms, and entrance - the brought heat streams are output. For rooms of pools we will consider them as uniform a tel. In this case is accepted that distributions of temperatures in these rooms is provided identical in all points [18-20].

The thermal energy of $\mathrm{Q}$ coming to the room is spent as was considered above, on heating of the room $Q_{R O O M}$ and on a covering of heatlosses through the protecting designs $Q_{W A L L}$, i.e.:

$$
Q=Q_{R O O M}+Q_{W A L L}
$$

For an infinitesimal interval of time $d \tau$, to the room energy will be brought $Q d \tau$, spent

1) on heating of $Q_{1} d \tau$ of the placement on $d t$ of degrees:

$$
Q_{1} d \tau=G_{R O O M} * C_{R O O M} d t
$$

and on a power consumption $Q_{2} d \tau$ covering through the protecting designs

$$
Q_{2} d \tau=k_{W A L L} * F_{W A L L} * \Delta t_{A} d \tau
$$

Then the differential equation of thermal balance of the warmed room of the pool can be written down in a look

or

$$
Q d \tau=Q_{1} d \tau+Q_{2} d \tau
$$

where

$$
Q d \tau=G_{\Pi О М} * c_{\Pi О М} d t+k_{\text {ОГР }} * F_{\text {ОГР }} * \Delta t_{B} d \tau
$$


$F_{W A L L}-$ The surface area of the protecting structures of the pool;

$\tau$ - Time;

$G_{R O O M}$ - Mass of the room of the pool;

$c_{R O O M}$ - Specific heat of material of the room;

$k_{W A L L}$ - Coefficient of a heat transfer of the protecting structures of the pool;

$\Delta t_{A}-$ Thermal head, $\Delta t_{A}=t_{A}-t_{O}, t_{A}-$ air temperature in the pool; $t_{O}-$ outside temperature.

Based on the received equation (11) it is possible to write down:

or

$$
Q=G_{R O O M} * c_{R O O M} \frac{d t}{d \tau}+k_{W A L L} * F_{W A L L} * \Delta t_{A}
$$

Entering designation

$$
\frac{Q}{k_{W A L L} * F_{W A L L}}=\frac{G_{R O O M} * c_{R O O M}}{k_{W A L L} * F_{W A L L}} * \frac{d t}{d \tau}+\Delta t_{A} .
$$

for the last equation we will write down

$$
T_{\text {ROOM }}=\frac{G_{R O O M} * c_{R O O M}}{k_{W A L L} * F_{W A L L}},
$$

$$
\frac{Q}{k_{W A L L} * F_{W A L L}}=T_{R O O M} * \frac{d t}{d \tau}+t_{A}-t_{O},
$$

or

where

$$
\frac{Q}{k_{O Г P} * F_{O Г P}}+t_{H}=T_{\Pi О M} * \frac{d t}{d \tau}+t_{B}
$$

$Q$ - The thermal energy coming to the room;

$T_{\text {ROoM }}$ - Constant of time of the warmed room,

In the equation (12) we will divide both parts into value $t_{A}$. As a result, we will receive

$$
\frac{Q}{k_{W A L L} * F_{W A L L} * t_{A}}+\frac{t_{O}}{t_{A}}=\frac{T_{R O O M}}{t_{A}} T_{R O O M} * \frac{d t}{d \tau}+1 \text {. }
$$

From the equation (13), passing into the area of complex variable $p$, and designating

$$
K=\frac{Q}{k_{W A L L} * F_{W A L L}}+t_{O},
$$

Let us receive transfer function of the warmed room of the pool on the channel amount of the brought heat - internal temperature indoors.

$$
W(p)_{R O O M}=\frac{K}{T_{R O O M} * p+1} .
$$
down

Similarly, considering multiple layers of wall designs, generally it is possible to write

$$
W(p)_{\Sigma}=\prod_{i=1}^{i=n} \frac{K_{i}}{T_{R O O M, i^{*}}+p+1},
$$

where $n$-quantity of layers of wall structures of the room of the pool.

\section{Conclusion}

Classification of pools of different function as objects with the difficult air-and-water environment is given in the article. Hydroclimatic parameters, which need to be controlled in rooms, including sanitary and hygienic requirements to parameters of a microclimate of the main rooms of the closed swimming pools, are considered. Problems of operation of the engineering systems providing maintenance of these parameters are considered. Systems of ventilation, heating, water treatment, heat supply, etc. concern to them. The stated mathematical model generally presented by expression (16) can be used for design of 
system of automatic control of temperature condition in the pool. In mathematical model, the main technological and design features of the pool as object of automation, which have to be considered by development of systems of automatic control, are considered. At the same time, it is necessary to take into account that the thermal state is influenced by losses of heat through ceiling overlapping that is considered in model (16), but also heat losses through the opened doors, influence of mass of water of a bowl of the pool and visitors of the pool. These questions have to be considered independently and add cumulative model of the considered object.

\section{References}

1. V.F. Drozdov, Otoplenie i ventilyaciya (Vysshaya shkola, Moscow, 1984)

2. B.V. Barkalov, H.H. Pavlov, S.S. Amirdzhanov, Vnutrennie sanitarno-tekhnicheskie ustrojstva (Strojizdat, Moscow, 1992)

3. Yu. Ya. Kuvshinov, Stroitel'stvo i arhitektura 4, 13-16 (1993)

4. A. Volkov, P. Chelyshkov, A. Sedov, Applied Mechanics and Materials 409-410, 630633 (2013)

5. A. Volkov, A. Sedov, P. Chelyshkov, Applied Mechanics and Materials 409-410, 630633 (2013)

6. A. Volkov, A. Sedov, P. Chelyshkov, Engineering 1, 27-29 (2014)

7. A. Volkov, A. Sedov, P. Chelyshkov, Procedia Engineering 2, 17-21 (2014)

8. A. Volkov, A.S edov, P. Chelyshkov, A. Doroshenko, Applied Mechanics and Materials 580-583, 3231-3233 (2014)

9. A. Volkov, A. Sedov, P. Chelyshkov, E. Kulikova, Mechanics and Materials 584-586, 753-756 (2014)

10. A. Volkov, A. Sedov, P. Chelyshkov, E. Kulikova, Mechanics and Materials 584-586, 757-760 (2014)

11. A. Volkov, A. Sedov, P. Chelyshkov, E. Kulikova, Mechanics and Materials 584-586, 760-763 (2014)

12. A. Volkov, A. Sedov, P. Chelyshkov, International Journal of Applied Engineering Research 10 (22), 43106-43107 (2015)

13. A. Volkov, P. Chelyshkov, A. Sedov, Robotics and Automation 1, 1193-1196 (2015)

14. A. Volkov, P. Chelyshkov, A. Sedov, Robotics and Automation 1, 1196-1199 (2015)

15. A. Volkov, A. Sedov, P. Chelyshkov, D. Lysenko, A. Doroshenko, International Journal of Applied Engineering Research 10 (22), 43269-43272 (2015)

16. A. Volkov, A. Sedov, P. Chelyshkov, E. Radzievskiy, International Journal of Applied Engineering Research 10 (22), 43273-43276 (2015)

17. A. Volkov, A. Sedov, P. Chelyshkov, B. Titarenko, G. Malyha, E. Krylov, Research Journal of Pharmaceutical, Biological and Chemical Sciences 7(3), 2416 (2016)

18. A. Volkov, A. Sedov, P. Chelyshkov, A. Pavlov, L. Kievskiy, International Journal of Applied Engineering Research 11 (3), 1645-1648 (2016)

19. A. Sedov, P. Chelyshkov, A. Afanasev, M. Vainstein, Y. Vilman, Y. Grossman, Research Journal of Pharmaceutical, Biological and Chemical Sciences 7(2), 1046 (2016)

20. A. Volkov, P. Chelyshkov, D. Lysenko, Theoretical Foundation of Civil Engineering, (2011) 